\title{
PRIVATIZAÇÃO DA GESTÃO E ORGANIZAÇÕES SOCIAIS NA ATENÇÃO À SAÚDE
}

\author{
PRIVATIZATION OF MANAGEMENT AND SOCIAL ORGANIZATIONS IN HEALTH CARE
}

PRIVATIZACIÓN DE LA GESTIÓN Y ORGANIZACIONES SOCIALES EN LA ATENCIÓN A LA SALUD

\author{
Maria de Fátima Siliansky de Andreazzi ${ }^{1}$ \\ Maria Inês Souza Bravo ${ }^{2}$
}

Resumo Este artigo procura discutir os avanços recentes da contrarreforma do Estado na saúde, particularmente na privatização da gestão para organizações sociais, e ainda apresenta um enfoque teórico explicativo desse fenômeno na atualidade. São investigadas as novas configurações do sistema de saúde brasileiro resultantes das interações entre o Estado e o mercado, mediante a abordagem dos anos que se iniciam no primeiro governo Lula, de 2003 até o presente, e enfoque das organizações sociais sediadas ou atuantes nos estados do Rio de Janeiro e de São Paulo. A despeito das expectativas criadas de mudanças substanciais na política econômica e social, o governo Lula manteve elementos importantes dos governos que o precederam a partir dos anos 1990. No plano estadual, o governo Sérgio Cabral Filho priorizou claramente a terceirização. É feita uma análise crítica dos argumentos empregados para impulsionar essa contrarreforma, utilizando-se algumas análises de casos. Ao final, elabora-se uma tese explicativa desse avanço à luz das transformações da base material e da superestrutura política do capitalismo contemporâneo e da formação social brasileira.

Palavras-chave organizações sociais; contrarreforma do Estado; saúde e mercado.
Abstract This article discusses the recent progress made in the counter-reform of the State in health, particularly in the privatization of the management for social organizations, and it also presents an explanatory theoretical focus on this phenomenon today. The new settings of the Brazilian health system resulting from the interactions between the State and the market are investigated by addressing the years beginning in the first Lula administration, from 2003 to the present, and the focus of the social organizations based or active in the states of Rio de Janeiro and São Paulo. Despite the expectations created for substantial changes in the economic and social policies, the Lula administration maintained important elements of governments that preceded him from the 1990s. At the state level, the Sérgio Cabral Filho administration clearly prioritized outsourcing. A critical analysis of the arguments used to boost this counter-reform is made based on a few case studies. At the end, an explanatory thesis is presented on the progress made in the light of the transformations of the material base, of the political superstructure of contemporary capitalism, and of the Brazilian social formation.

Keywords social organizations; counter-reform of the State; health and market. 


\section{Introdução}

As mudanças da gestão dos programas e unidades de saúde do Estado, nos anos recentes, por meio dos chamados novos modelos de gestão, trazem desafios importantes sobre a configuração do sistema de saúde brasileiro. Tais alterações têm gerado mudanças legislativas e criação de novas personalidades jurídicas ou são impulsionadas por elas, como as organizações sociais (OSs) e as fundações estatais de direito privado. Especialmente a primeira dessas instituições não é nova. É fruto do programa de contrarreforma ${ }^{3}$ do Estado, elaborado por Bresser Pereira, em 1995, e já de antiga implementação no estado de São Paulo. Entretanto, particularmente a partir do final dos anos 2000, observa-se uma aceleração no tempo e maior distribuição no espaço nacional de sua adoção por diferentes governos estaduais e municipais.

Na mesma conjuntura também se observa o notável processo de concentração, fusões e aquisições, concomitante à abertura de capital de empresas de seguros e serviços de saúde privados do país. Confirmando uma tendência já apontada por Cordeiro, nos anos 1980 (Cordeiro, 1984), e Andreazzi, em 1990 (Andreazzi, 1991), estão sendo criados grandes grupos econômicos - os chamados conglomerados. Estes reúnem no seu interior empresas de asseguramento privado e de prestação de serviços de saúde, em consolidações facilitadas pelas suas ligações prévias com o capital bancário, setor segurador e processos de capitalização por meio da abertura de capitais. Os dois fenômenos, aparentemente, não estariam relacionados - um decorrente de opções de políticas públicas; o outro, consequência do próprio desenvolvimento do capital no setor de atenção privada à saúde, semelhante a mudanças do mercado de asseguramento e serviços privados de saúde estado-unidense observadas desde os anos 1980 (Salmon, 1985).

Entretanto, ambos são projetos emanados do mesmo campo, as instituições financeiras internacionais, especialmente o Banco Mundial. Esta organização ganha destaque como impulsionadora de propostas de 'reforma' do Estado e, especificamente, de políticas públicas, como a saúde, a partir dos anos 1980 (Mattos, 2001), em paralelo a medidas que o sistema capitalista vai implementar para contrarrestar sua crise econômica - que se torna um aspecto crônico de sua existência, a partir de então.

Não cabe aqui detalhar todos os aspectos dessas reformas, já estudadas em detalhe em outros trabalhos (Laurell, 1992; Rizzotto, 2000). Cabe destacar apenas os projetos relacionados às reformas da administração pública e da saúde. No primeiro caso, elas se pautam na redução dos gastos e em um pretenso aumento da eficiência. Como medidas práticas, estabelecem a flexibilização de procedimentos, a separação entre formulação e implementação e a introdução de elementos de mercado na administração pública. Propõem também novas formas de provisão dos serviços, baseadas na criação de en- 
tidades não estatais, na descentralização e na privatização de funções públicas, tendo como pré-requisito a redução do tamanho do Estado e dos gastos públicos (Pinto, 2000). Tais medidas foram propagadas sob a égide de teorias administrativas que ficaram conhecidas como Nova Gestão Pública (Sano e Abrúcio, 2008). Se, na década de 1980, a preocupação principal foi o ajuste das contas públicas, mais recentemente a ênfase se deslocou para as reformas institucionais, visando ao aumento da capacidade do Estado para viabilizar o sucesso das medidas de ajuste e atenuar suas consequências sociais (Machado, 1999).

Nesse contexto, as reformas da saúde procuraram promover, inicialmente, a descentralização, o fomento à criação de mercados privados de asseguramento, a introdução de copagamentos nas unidades públicas de saúde e a focalização do Estado nas populações ditas 'pobres'. Do Relatório do Banco Mundial de 1993, emerge a proposta de introdução de um pacote básico de medidas consideradas custo-efetivas, que o Estado deveria bancar por meio de impostos, sem cobrança aos cidadãos (Andreazzi, 1997).

Na América Latina, o Chile foi o precursor desse modelo, em sua reforma imposta pelo governo ditatorial de Pinochet, entre 1978 e 1980, paradigmática de uma reforma liberal radical (Labra, 2001). A focalização das políticas públicas nos países pobres é uma estratégia diferente do que ocorre nos países centrais, em razão da pobreza e da concentração de renda que impedem a expansão do mercado para a maioria da população, sem subsídios apropriados. O Estado, portanto, mantém um papel preponderante na atenção primária de saúde e no seu financiamento do setor privado para os demais níveis de atenção.

A evolução das estratégias do Banco Mundial para a saúde estatal vai desaguar em propostas que buscam promover a separação entre financiamento e provisão de serviços visando à reestruturação do papel do Estado, agora regulador de redes de unidades privadas e públicas, introduzindo mecanismos de competição nos sistemas de saúde, que foram diretrizes seguidas pela reforma colombiana de 1991/1993 (Almeida, 2002; Mendes, 2001). Nesta reforma, mediante contribuições compulsórias para a saúde, o segurado tem o direito de escolher o provedor, ou administrador de seu fundo. O governo funciona como regulador de todo o sistema e financiador de um conjunto de serviços essenciais (ou básicos). Por meio do modelo de captação, repasses que o Estado provê com valores fixos per capita, prestadores públicos e privados competiriam entre si pela demanda (Mendes, 2001).

A despeito de não ter havido no país projetos profundos de contrarreformas do sistema de saúde, seja nos termos chilenos, seja nos colombianos, as transformações em curso apontam para cenários em que esses projetos não estão ausentes, pois criam e fortalecem sujeitos sociais com interesses econômicos associados. $\mathrm{O}$ viés franca e fortemente empresarial que parece estar 
estruturando o sistema de saúde brasileiro, a partir da década de 1990, representa um contraponto a toda a base de estruturação do Sistema Único de Saúde (SUS), ameaçando as premissas de equidade e universalidade que nortearam sua criação.

Este trabalho procura mapear os avanços recentes da contrarreforma do Estado na saúde, particularmente na privatização da gestão para OSs. Apresenta ainda um enfoque teórico explicativo desse fenômeno na atualidade, pautando-se em um estudo histórico, com base documental. É parte de um projeto de pesquisa, financiado pela Fundação de Amparo à Pesquisa do Estado do Rio de Janeiro (Faperj), que visa investigar as novas configurações do sistema de saúde brasileiro que resultam das interações entre o Estado e o mercado, abordando os anos que se iniciam no primeiro governo Lula, em 2003, até o presente e enfocando as organizações sociais sediadas ou atuantes no estado do Rio de Janeiro.

\section{O período de análise: os anos do PT no poder nacional, a conjuntura locorregional e a saúde}

O período que se inicia com o governo Lula (2003), a despeito das expectativas criadas de mudanças substanciais na política econômica e social, manteve elementos importantes dos governos que o precederam a partir dos anos 1990. Boito Jr. (2003) afirma ter havido uma hegemonia neoliberal que manteve as orientações da política econômica e de gestão do trabalho: a abertura comercial, a desregulamentação financeira, a privatização, o ajuste fiscal e o pagamento da dívida, a redução dos direitos sociais, a desregulamentação do mercado de trabalho, a desindexação dos salários e a contrarreforma da previdência. Na esfera da seguridade social, Boschetti (2007) encontrou importantes similaridades no tratamento dado pelo governo Lula a cada um dos seus componentes: assistência, previdência e saúde.

Houve, de acordo com o já exposto, uma continuidade nas diretrizes da contrarreforma do Estado de Bresser Pereira, de 1995, reeditadas em variadas formas nas políticas de privatização da gestão de unidades públicas de saúde (Graneman, 2007). No campo das políticas sociais, inclusive a saúde, destaca-se a ênfase em programas focais como o Bolsa Família (Marques e Mendes, 2005), além de outros como os programas Saúde da Família e Agentes Comunitários de Saúde (Pacs). Bravo $(2004,2006)$ identifica contradições no governo Lula, mas com ênfase na focalização, na precarização, na terceirização dos recursos humanos, no desfinanciamento e na falta de vontade política para viabilizar a concepção de seguridade social.

Ressalta-se no segundo mandato (2005), com perspectivas de continuidade na administração Dilma (2011), a ênfase numa política de franco sub- 
sídio do Estado ao mercado no âmbito do Programa de Aceleração do Crescimento. É importante destacar, no caso da saúde, o Programa Mais Saúde do Ministério da Saúde (2007-2011) e a perspectiva que toma o setor saúde como um setor de produção de riqueza, o chamado Complexo Produtivo da Saúde (Gadelha, 2012). Metas do programa implicaram uma aceleração da construção de novos equipamentos de saúde, como as unidades de pronto atendimento (UPAs), muitas delas gerenciadas por OSs. Outras estratégias inovadoras, tais como parcerias público-privadas para investimentos na atenção à saúde e Fundação Estatal de Direito Privado, passam a fazer parte do vocabulário corrente do Ministério da Saúde.

No plano estadual, houve dois governos no período: Rosinha Garotinho (2003-2006) e Sérgio Cabral Filho (início 2007). O primeiro não conseguiu debelar a situação da rede de atenção à saúde, afetada por problemas de desfinanciamento, o que também ocorria nacionalmente. No Rio de Janeiro, entretanto, esta situação foi agravada pelo desvio de verbas para programas assistencialistas (Bravo e Menezes, 2007).

Cabral assume denunciando o genocídio na saúde e compromete-se com a implantação do projeto das UPAs no Estado, numa articulação mais estreita com a agenda federal. Defende o projeto das fundações estatais de direito privado para a gestão das unidades públicas. Em 2011, é autor do projeto de lei que permite a transferência de unidades estaduais de saúde para a gestão de OSs.

Quanto ao município do Rio de Janeiro, após mandato de César Maia, que vinha de vários governos numa orientação mais voltada ao fortalecimento da administração direta, assume em 2009 Eduardo Paes, aliado de Sérgio Cabral, com orientação privatizante definida. No seu mandato, a Secretaria Municipal de Saúde patrocina legislação referente às OSs, em 2009.

\section{O avanço da contrarreforma do Estado brasileiro na saúde: a privatização da gestão de unidades públicas}

As diretrizes da contrarreforma do Estado na saúde, em seu componente dos modelos de gestão de unidades públicas, procuraram se materializar por meio de leis federais, mas também das leis estaduais e municipais. Além das fundações estatais de direito privado que não serão aqui abordadas, elas trataram da criação das OSs e das organizações da sociedade civil de interesse público (Oscips). No plano federal, foram as leis n. 9.637, de 15/5/1998, e 9.790, de 23/03/1999, respectivamente. Essa normatização não tem sido feita sem resistências da sociedade, encontrando-se no Supremo Tribunal Federal uma ação ajuizada arguindo a constitucionalidade na Lei das OSs (Adin 1.923/98). 
Um dos mecanismos básicos para que estados e municípios aderissem a essas mudanças foi a Lei de Responsabilidade Fiscal (lei complementar n. 101, de 4/5/2001), que impõe um teto de 56\% da receita corrente líquida com despesas de pessoal criando condicionalidades financeiras relativas aos gastos com saúde, sabidamente intensivos em pessoal. Há razoável consenso de que ela foi uma das molas mestras da política financeira neoliberal e da contrarreforma do Estado, avançando, ainda, sobre a autonomia dos entes subfederais (Fleury et al., 2010).

Além disso, o modus operandi da administração direta da saúde passa a ter questionamentos vindos de diferentes campos e com argumentos variados, não apenas aqueles assentados na Nova Gestão Pública. O documento do Banco Mundial de 2007 defendeu a ideia de que as principais deficiências que afetariam a qualidade do cuidado nos hospitais públicos brasileiros estavam relacionadas às áreas de suprimento de medicamentos, de gestão das pessoas e de equipamentos e insumos médicos (World Bank, 2007). Nogueira ressalta nessa linha a

reduzida autonomia técnico-administrativa, devido às normas e procedimentos típicos da administração direta, limitações criadas pela Lei de Responsabilidade Fiscal, especialmente quanto à admissão e expansão dos recursos humanos; falta de agilidade nos processos licitatórios para a aquisição de equipamentos e insumos de necessidade urgente; dificuldades de incorporação de pessoal mais qualificado e de certas especialidades, inclusive porque alguns profissionais, a exemplo dos anestesistas e oftalmologistas, recusam-se a prestar concurso público ou prestam, mas não assumem as vagas disponíveis (Nogueira, 2010, p. 36).

Correntes oriundas do próprio movimento da reforma sanitária apontam outras características como impeditivas de melhor desempenho do SUS, defendendo a privatização da gestão. Até o combate ao patrimonialismo é usado como argumento, atribuindo-se às novas organizações privadas maior profissionalismo na gestão de funções públicas (Paim e Teixeira, 2007).

A implementação da contrarreforma neoliberal do Estado se propõe efetivar a execução das políticas públicas por uma ampla gama de instituições 'não governamentais', 'não lucrativas' e voltadas ao desenvolvimento social - especialmente em setores não considerados 'atividades exclusivas de Estado' ou 'competitivos', em que a prestação de serviços de saúde está classificada no Plano Diretor da Reforma do Estado proposta por Bresser Pereira (Bresser Pereira, 1996). Isso daria origem a uma 'esfera pública não estatal', constituída por 'organizações da sociedade civil de interesse público' (Iamamoto, 2006). De acordo com Martins (1998), tal situação tem sido proclamada como o advento de uma era pós-burocrática, na qual as mazelas da burocracia estatal seriam, por fim, equacionadas com maior racionali- 
dade no seio da própria sociedade. Ainda para Iamamoto, o conceito de terceiro setor articulado com a sociedade civil "tende a ser interpretado como um conjunto de organizações distintas e 'complementares', destituídas dos conflitos e tensões de classe, onde prevalecem os laços de solidariedade" (Iamamoto, 2006, p. 31). Entretanto, ao contrário dos princípios de uma cidadania universal e igualitária,

os projetos levados a efeito por organizações privadas apresentam uma característica básica, que os diferencia: não se movem pelo interesse público e sim pelo interesse privado de certos grupos e segmentos sociais, reforçando a seletividade no atendimento, segundo critérios estabelecidos pelos mantenedores (Iamamoto, 2006, p. 31).

Em 2007, de setenta OSs criadas no país, a saúde era o maior setor contemplado, com 25 organizações, 16 delas em São Paulo, uma no Espírito Santo, três na Bahia, três no Pará e uma em Goiás (Sano e Abrúcio, 2008). Informações preliminares colhidas na mídia impressa e eletrônica mostram que esse processo tem se acelerado nos últimos anos, com surgimento de organizações sociais em Santa Catarina, novas OSs no Pará e, recentemente, em Mato Grosso, Rio Grande do Norte, Goiás e Distrito Federal.

No Rio de Janeiro, a adoção desse modelo ocorre na administração de Eduardo Paes, iniciada em 2009, que fez opção de trabalhar com OSs na implantação da Saúde da Família e das UPAs, documentada no Plano Municipal de Saúde de 2009-2013. A lei municipal das OSs (lei n. 5.026) foi sancionada em maio de 2009, a despeito de posição contrária do Conselho Municipal de Saúde. Em 2009, foram firmados contratos com oito OSs e, em 2010, com mais três, ampliando-se contratos com as anteriormente qualificadas. No final de 2011, segundo informativo da Comissão de Qualificação das Organizações Sociais, publicado no Diário Oficial do Município do Rio de Janeiro em 30 de dezembro de 2011, haviam sido qualificadas como OSs 37 entidades 'sem fins lucrativos', sendo 21 na área da saúde (Mattos, 2012). ${ }^{4}$

No âmbito estadual, em setembro de 2011 foi votada na Assembleia Legislativa do Rio de Janeiro o projeto de lei n. 767/11, que permite ao Poder Executivo, autor da proposta, a delegação da administração de unidades da saúde a OSs, qualificadas como tal entre entidades de direito privado - a despeito de manifestações de vários segmentos sociais contrários à medida.

Essas experiências não têm se dado sem contradições. No âmbito do Judiciário, existem diferentes interpretações que questionam a sua legalidade. Há resistências da sociedade civil e dos trabalhadores do setor saúde à sua implementação. Entretanto, com exceção de São Paulo, onde a implantação das OSs é mais antiga, seus impactos se encontram ainda pouco documentados. 
Diversos fatos que contestam o profissionalismo e a ausência de práticas patrimonialistas a partir da implantação das OSs vêm sendo apresentados. Entre setembro de 2007 e junho de 2008, foi instalada uma comissão parlamentar de inquérito na Assembleia Legislativa de São Paulo sobre remuneração dos serviços médico-hospitalares. Raul Marcelo, deputado estadual pelo PSol/SP, foi sub-relator sobre OSs (Assembleia Legislativa do Estado de São Paulo, 2008). Alguns resultados a que chegou essa Comissão Parlamentar de Inquérito (CPI) serão a seguir apresentados. Quanto ao pessoal, a definição sobre contratação, em qualquer forma de vínculo, é de decisão exclusiva da OS. Há uma inequívoca flexibilização das relações de trabalho vis-à-vis ao regime jurídico dos funcionários públicos. Têm sido altos os índices de rotatividade apresentados. A porventura existência de programas de educação permanente, tão necessária numa área como a saúde, com intenso dinamismo tecnológico, tem sido contrabalançada em seus impactos positivos pela instabilidade funcional. Com respeito à escolha das OSs, um dos aspectos mais criticados no debate legislativo foram os mecanismos discricionários do Poder Executivo de contratação por dispensa de licitação.

Auditoria técnica realizada pelo Tribunal de Contas do Município noticiada no jornal O Estado de S. Paulo (O Estado de S. Paulo, 2010) assinalou que a Prefeitura de São Paulo não teve controle sobre o total de R 1,4 bilhão que saíram dos cofres municipais, em 2009, para o pagamento dos serviços feitos pelas OSs na área da saúde. Apesar da existência de um órgão na Secretaria Municipal da Saúde para monitoramento e avaliação das OSs - o Núcleo Técnico de Contratação de Serviços em Saúde -, há problemas no controle e na fiscalização das entidades. O trabalho do órgão da secretaria é "falho e ineficiente, uma vez que as prestações de contas da contratada foram aprovadas contendo erros e inconsistências nos dados" (O Estado de S. Paulo, 2010), cita o documento do Tribunal. Outra irregularidade encontrada pelos auditores foi a inexistência de contas correntes específicas para repasses e movimentação de valores das OSs.

No caso do Distrito Federal (DF), documento do Ministério Público do Trabalho e do Ministério Público de Contas do DF de 2010 (Redação Mais Comunidade, 2010) apontou várias irregularidades no hospital de Santa Maria, gerido pela Real Sociedade Espanhola, como falta de planilhas de custo, denúncias de improbidade administrativa contra os gestores da OS, pendências com o Tribunal de Contas e salários altos pagos a diretores. Tais irregularidades teriam motivado a intervenção da Secretaria de Saúde, mediante Termo de Ajustamento de Conduta, assinado com o Ministério Público.

Em que medida as OSs se limitariam a ser parte de uma esfera quase pública, ou seja, se enquadrariam como terceiro setor, nem estado nem mercado? No estado de São Paulo, de acordo com o Relatório da CPI da Assembleia Legislativa (Assembleia Legislativa do Estado de São Paulo, 2008), 
anteriormente mencionado, constatou-se que sob o guarda-chuva do estatuto jurídico de organização sem fins lucrativos, exigência da legislação para ser certificada pelo Estado, abriga-se uma intensa contratação de serviços específicos para empresas lucrativas: o relatório se refere a 'quarteirização' e até 'quinteirização' dos serviços prestados. Ao terem a permissão de contratar todo tipo de serviços, sem controle público, o que ocorre é que empresas que prestam serviços hospitalares são convidadas a atuar dentro dos hospitais públicos e subcontratam outras. De acordo com o relatório "A terceirização de laboratórios públicos pelo governo do estado de São Paulo", elaborado pelo Sindicato dos Trabalhadores Públicos na Saúde de São Paulo (SindSaúde-SP), em dezembro de 2007 (O Estado de S. Paulo, 2010), existem casos de uma terceirização de atendimento laboratorial na rede pública, por meio das OSs. De acordo com Angelo D’ Agostini, diretor-executivo do SindSaúde-SP, “Funciona da seguinte maneira: os centros estaduais de análises clínicas (responsáveis por serviços laboratoriais na rede pública) são administrados por uma OS, que por sua vez contrata os serviços de uma empresa privada" (O Estado de S. Paulo, 2010).

Os relatórios concluem pela manutenção e amplificação das práticas de extração de rendas por parte dos agentes estatais contratantes das OSs: gerando todo tipo de favorecimentos, acordos e - por que não? - relações com partidos e parlamentares, financiamento de campanhas, entre outros (O Estado de S. Paulo, 2010). Tal conclusão não reforça o argumento de Paim e Teixeira (2007) quanto às vantagens das OSs no combate ao patrimonialismo da administração pública estatal.

Para as unidades públicas de saúde, nessa nova perspectiva, vai-se delineando um modus operandi distinto. A perspectiva inicial da política do Banco Mundial era de que elas cobrassem uma parte do atendimento aos usuários, o que nunca gerou um volume expressivo de recursos, dado o perfil socioeconômico de sua demanda, onde isso foi implementado (Andreazzi, 1997). Daí segue outra perspectiva de captação de recursos, especialmente nos países chamados de renda média, entre eles o Brasil. O projeto da contrarreforma do Estado de Bresser, com a criação das OSs, é claro na necessidade de passar essas unidades para a gestão de entes privados. E que elas tivessem autonomia financeira para captação de recursos no mercado privado, que se desenvolvia no país por meio de seguros privados de saúde, mediante um plano de negócios, em que o financiamento público passa a ser complementar (Andreazzi, 1999).

A materialização de tal estratégia pode ser visualizada no final de 2010, em São Paulo, onde o Plenário da Assembleia Legislativa aprova, na véspera dos feriados de final de ano, o projeto de lei complementar n. 45/2010, do Executivo, agora lei complementar n. 1.131, de 27/12/2010, e regulamentada pelo governador Geraldo Alckmin mediante o decreto n. 57.108/2011, que 
altera a regulamentação das organizações sociais no estado de São Paulo. Por meio dessa lei, as OSs que geram hospitais estaduais passam a poder utilizar até $25 \%$ de sua capacidade instalada para atender pacientes privados com ou sem planos de saúde 5 - o que significa que o investimento feito com recursos públicos, extraídos dos impostos pagos por toda a população brasileira, será disponibilizado de forma não igualitária, ao permitir uma entrada diferenciada para aqueles que tenham fontes privadas de financiamento. Com isso, os objetivos completos da contrarreforma do Estado, antes encobertos para amainar as resistências existentes, se revelam - não apenas reformas gerenciais objetivando aumentar a eficiência do Estado com a flexibilização de regras processuais, ou seja, contratação de pessoal e compra de material à semelhança dos existentes no setor privado, mas controle por meio de resultados, que preservavam o acesso exclusivamente público da clientela.

Tal disponibilidade de leitos em unidades que eram exclusivamente públicas reforça a extensão a curto prazo dos planos privados de saúde para as rendas menores, ao viabilizar a utilização de uma capacidade instalada existente e montada com recursos públicos, sem nenhuma necessidade de investimentos por parte do setor privado. A pesquisa Assistência Médico-Sanitária na sua versão de 2009 (INSTITUTO BRASILEIRO..., 2009) revelou que a oferta privada de leitos privados e totais no estado de São Paulo vem caindo consistentemente. De 2005 a 2009, segundo informações do Sistema de Beneficiários da Agência Nacional de Saúde Suplementar, que constam de sua página eletrônica (www.ans.gov.br), a cobertura de planos de saúde do estado de São Paulo cresceu 16,8\%, enquanto a oferta de leitos privados cresceu apenas 3,8\%. Por sua vez, as OSs propiciaram a expansão da rede pública desde a sua criação, despertando a cobiça dos planos de saúde. Esses leitos são alvo da nova lei complementar, que viabiliza a redução do já insuficiente orçamento público para a saúde, ao permitir a substituição, nos contratos de gestão com as organizações sociais, de recursos públicos para custeio por recursos privados. Tal desvio garante o permanente ajuste fiscal para equilíbrio das contas públicas e o desvio do orçamento para manutenção da política de juros altos, endividamento do Estado e políticas sociais focais compensatórias que proporcionam a estabilização política do governo, sem resolver os problemas de fundo da população.

\section{Interpretações à luz das transformações da base material e da superestrutura política do capitalismo contemporâneo e da formação social brasileira}

As políticas de privatização da gestão de unidades públicas de saúde que hoje se implementam de forma acelerada obedeceriam apenas aos ditames 
econômicos, entre os quais o equilíbrio de contas públicas e legitimação do Estado por meio da focalização, como enfatiza grande parte da literatura crítica desse modelo?

Uma das possíveis explicações reside na análise das diferenças entre o modelo das organizações sociais e os modelos tradicionais de contratação de serviços privados de saúde pelo SUS. Neste último caso, o investimento em capital é de responsabilidade do setor privado, embora possa contar com políticas diferenciadas de empréstimos por parte de instituições financeiras públicas - situação no passado da Caixa Econômica Federal, por meio do Fundo de Apoio ao Desenvolvimento Social, e o caso atual do Banco Nacional de Desenvolvimento Econômico e Social. Há um risco inerente à atividade econômica. Nas OSs, o investimento e o custeio são do Estado; trata-se de uma terceirização de gestão. Para a lei n. 8.080/1990, a contratação de serviços privados deve ser complementar quando não existe capacidade instalada pública local - o que não ocorre com a terceirização, permitindo ao Estado passar para a iniciativa privada unidades novas e existentes. O não respeito à lei n. 8.080 deve ser levado em conta ao se analisar a crescente judicialização da política de saúde.

Há outro aspecto a ser considerado: a criação de possibilidades de extração de rendas para grupos econômicos que são criados por dentro do Estado, em articulação estreita com grupos de poder. Tal questão tem sido amplamente discutida no âmbito dos pareceres do Judiciário e dos tribunais de contas que analisam os contratos do Estado com as OSs, conforme relatado na seção anterior.

Há que se levar em conta as conjunturas internacional e nacional do setor, de maturidade do complexo médico-industrial-financeiro da saúde sob a dominância de grandes empresas multinacionais dos países ricos, cujos padrões de atenção à saúde se disseminam em associação com grandes empresas nacionais de seguros e serviços de saúde. O fundo público, na conjuntura de crise crônica do capitalismo, é chave para a manutenção da taxa de acumulação de todo o setor, de várias formas. Não é difícil supor que toda uma sorte de entrelaçamentos entre o grande capital e as organizações privadas gestoras de unidades públicas de saúde existe ou existirá, como já se pode identificar em São Paulo, pelas relações de terceirização de OSs para empresas lucrativas.

Tal hipótese vai se assentar numa compreensão do capitalismo, da formação econômico-social brasileira e da dinâmica do setor saúde. Em linhas gerais: na economia política marxista, particularmente na enunciação de Marx (1980) sobre a tendência a crises de superprodução; nos estudos recentes sobre a financeirização, as configurações contemporâneas das grandes empresas e o papel dos serviços, encontrada em teóricos franceses da Escola da Regulação, como Chesnais $(1996,2005)$ e Gadrey (1996); finalmente, quanto 
à dinâmica atual do setor saúde, num diálogo com teóricos estado-unidenses sobre o complexo médico-industrial daquele país (Andreazzi e Kornis, 2009). Destes trabalhos, destaca-se a análise de Salmon (1995) sobre as instituições não lucrativas, de caráter religioso e comunitário, que foram centrais na formação da rede de atenção à saúde nos Estados Unidos, na primeira metade do século XX, e sua posterior subsunção ao grande capital.

Do ponto de vista da base material, ressalta-se a tendência a crises periódicas de superprodução e de queda da taxa de lucros como características centrais do capitalismo (Marx, 1980 [1867]), estando o conjunto do mundo, desde o final dos anos 1970, vendo um longo período sob essa égide.

Os serviços de saúde como área de expansão do capital exemplificam a tendência já identificada por Marx de penetração de relações capitalistas de produção em todas as esferas da produção material, em que anteriormente existiam relações artesanais ou nas quais a caridade ou o Estado imperavam. $\mathrm{Na}$ conjuntura de crise, tais serviços podem se tornar campo de existência de contratendências à crise geral do capitalismo, quando se recomenda a privatização do Estado para que eles se tornem objeto de valorização.

A hipertrofia da órbita financeira desde o último quartel do século XX um modo de estruturação da economia capitalista - constitui o resultado e a face mais característica dessa longa conjuntura de crise. Nesse novo quadro, denominado por Chesnais (1996) de mundialização, há uma notável aceleração da concentração de capital, sob a égide dos países centrais. Tal processo se intensifica nos anos 2000, tendo como uma de suas principais consequências a contínua hipertrofia do setor financeiro. Encontra-se também em Braga (1998) o entendimento da financeirização global como um modo de ser do sistema capitalista. Trata-se de a crescente tendência à predominância dos ganhos em mercados financeiros globais ser mais importante do que em atividades produtivas (produção e comércio), gerando um desvio de recursos a serem investidos na produção para a especulação. Essa financeirização tem conferido um dinamismo mínimo à renda nacional e à acumulação de capital produtivo.

Outro elemento importante dessa nova etapa do capitalismo seria a terceirização, entendida como a atual importância do setor terciário como gerador de produto e mobilizador de força de trabalho, que caracteriza não só os países industrializados, mas também aqueles países de industrialização mais recente. Chesnais (1996) deixa claro que o setor de saúde privado torna-se uma das prioridades para o investimento produtivo, tal como telecomunicações, mídia e serviços financeiros. Gadrey (1996) identifica uma complementaridade atual no consumo e na produção entre a indústria e os serviços, em que a formação de complexos integrados indústria-serviços, como o complexo médico-industrial-financeiro, representaria uma nova articulação produtiva. Assim, os serviços passariam a fazer parte das estra- 
tégias de competição das indústrias; escoariam, inclusive, a produção de bens industriais, o que ocorre não apenas com a saúde.

Um aspecto peculiar da conjuntura da mundialização do capital tem sido a internacionalização das empresas de serviços (Horta, Souza e Waddington, 1998). Em meados dos anos 1990, os investimentos diretos em serviços representaram $40 \%$ do total, com a principal parcela cabendo aos serviços financeiros. Um marco do processo foi o ano de 1995, quando foi assinado o Acordo Geral de Comércio de Serviços, por meio do qual os países signatários comprometeram-se a uma progressiva liberalização de seus mercados internos (Adlung e Carzaniga, 2001; Santos e Passos, 2010).

Quanto à formação do Estado brasileiro, entende-se que há um razoável debate no país acerca do seu caráter, especialmente quanto à relação entre o capitalismo industrial e a modernização do Estado, que não será aqui aprofundado. O que se quer assinalar é que a modernização impulsionada por essa industrialização não foi contrária às tradicionais relações de produção, mantendo elementos da superestrutura jurídica e política, em particular o caráter do Estado. Sodré (1962) resume o processo afirmando ser o Brasil um exemplo de desenvolvimento à moda prussiana em que avança a penetração capitalista, mas "os restos feudais vão sendo conservados e o monopólio da terra zelosamente defendido" (Sodré, 1962, p. 387) o que se reflete nas contradições existentes entre diversos setores no próprio aparelho do Estado.

Em outra perspectiva teórica, em aspectos importantes bastante diferentes de Sodré (1962), mas com incisiva descrição detalhada do fenômeno, Faoro (1958) afirma que um dos traços marcantes do Estado brasileiro, que remonta à própria colonização, é o patrimonialismo, o qual viria persistindo em diferentes formas até o período Vargas, quando o autor encerra sua análise. Faoro (1958) reflete uma relação entre o Estado centralizador e as possibilidades concretas de colonização, descentralizadas. Nela se estabelece e cristaliza uma simbiose caracterizada pelo pinçamento das riquezas produzidas pelo país por parte de uma camada dirigente do aparelho do Estado, segundo o autor, até relativamente autônoma (o estamento) em troca do tráfico de influências necessárias para desembargar procedimentos necessários ao andamento dos negócios dos correspondentes locais do poder. Há um debate contemporâneo em torno de um neopatrimonialismo, sobretudo vinculado à literatura sobre corrupção (Domingues, 2008), em que é mister a retomada de análises desses processos no Estado brasileiro referentes ao objeto de análise, que envolve as relações entre Estado e mercado.

Para Lazzarini (2010), baseado teoricamente em Faoro (1958), caracteriza-se no Brasil um capitalismo de laços, entendido como um emaranhado de contatos, alianças e estratégias de apoio gravitando em torno de interesses políticos e econômicos. É um modelo assentado no uso de relações para 
explorar oportunidades de mercado ou para influenciar determinadas decisões de interesse. Se para Lazzarini (2010) isso seria uma distorção de mercado como um tipo ideal, para Evans (1995), o próprio mercado é embebido numa rede de relações sociais.

Entendemos, enfim, que as OSs, por priorizarem as transferências de recursos do Estado para entes de direito privado, em vez de fortalecerem a administração própria, respondem aos ditames do ajuste fiscal demandado pelas agências financeiras internacionais pela flexibilização, que proporciona interrupção da prestação dos serviços de saúde. Além disso, na fase que nos encontramos desde o segundo governo Lula, de manutenção de taxas de crescimento da economia por meio de forte transferência do fundo público, de variadas formas, para o setor privado - como o Programa de Aceleração do Crescimento -, as OSs podem estar servindo para, atendendo aos interesses do complexo médico-industrial-financeiro, especialmente do industrial, permitir a manutenção e o fortalecimento de grupos de poder favoráveis a essa política no aparelho de Estado. Outros interesses desse complexo no campo dos serviços privados de saúde podem também estar contemplados por meio da quarteirização dos seus componentes mais lucrativos para grandes empresas, como laboratórios e diagnóstico por imagem.

Diversas correntes teóricas da economia política, liberais, weberianas e marxistas, têm procurado compreender esse fenômeno do entrelaçamento do Estado com as empresas privadas como uma característica importante de países de capitalismo atrasado ou dependente, como o Brasil. Chamamos, por isso, a atenção para que a literatura crítica sobre a reforma do Estado no Brasil também leve em conta esse aspecto da nossa formação econômico-social, mesmo entendendo, assim como Marx, que no capitalismo tanto o Estado está a serviço, de modo geral e em última análise, da reprodução do capital, como a concorrência entre os capitais se dá em todos os planos em que o mercado se faz presente, inclusive e especialmente nas políticas a ele direcionadas (Marx, 1984 [1885]). Estudos de caso e demais pesquisas empíricas, como essa da qual este trabalho faz parte, enriquecem sua perspectiva de análise tomando esses elementos em conta.

\section{Algumas reflexões}

Algumas questões são centrais para o aprofundamento do estudo: que papel representam as organizações sociais como novas gestoras privadas dos programas e unidades de saúde do Estado? Qual é o caráter econômico-político dessas novas instituições? Resumem-se a uma forma gerencial alternativa à estatal, mas preservando as diretrizes do Estado democrático, apenas de modo mais eficiente e sensível às demandas dos cidadãos? Perpetuam em novas e 
mais facilitadas formas as tradicionais práticas patrimonialistas do Estado brasileiro? Inserir-se-ão no circuito principal de acumulação de capital no setor saúde e de que formas?

Tais perguntas engendram explicações múltiplas, porém articuladas em seus elementos individuais e investigações empíricas que evidenciam os laços existentes entre o Estado e organizações não governamentais sob o pano de fundo da consolidação do grande capital financeiro no setor saúde.

\section{Colaboradores}

As duas autoras participaram conjuntamente de todas as etapas de elaboração do artigo, desde a concepção até a redação final.

Resumen Este artículo trata de discutir los últimos avances en la contrarreforma del Estado en la salud, en particular, en la privatización de la gestión para organizaciones sociales, y también presenta un enfoque teórico explicativo de este fenómeno en la actualidad. Se investigan las nuevas configuraciones del sistema de salud brasileño como resultado de las interacciones entre el Estado y el mercado, abordando los años a partir del primer gobierno de Lula, desde 2003 hasta el presente, y el enfoque de las organizaciones sociales con sedes o actuantes en los estados de Río de Janeiro y São Paulo. A pesar de las expectativas creadas de cambios sustanciales en la política económica y social, el gobierno de Lula mantuvo elementos importantes de los gobiernos que le precedieron desde la década de 1990. A nivel de estado, el gobierno de Sérgio Cabral Filho claramente priorizó la subcontratación. Se hace un análisis crítico de los argumentos utilizados para impulsar esta contrarreforma, utilizando algunos análisis de casos. Por último, se elabora una tesis explicativa de este avance a la luz de las transformaciones de la base material y de la superestructura política del capitalismo contemporáneo y de la formación social brasileña.

Palabras clave organizaciones sociales; contrarreforma del Estado; salud y mercado. 


\section{Notas}

1 Universidade Federal do Rio de Janeiro, Rio de Janeiro, Brasil.

Doutora em Saúde Coletiva pela Universidade do Estado do Rio de Janeiro.

<siliansky@iesc.ufrj.br>

Correspondência: Rua José Higino, 253/201, Tijuca, CEP 20520-201, Rio de Janeiro, Rio de Janeiro, Brasil.

2 Universidade do Estado do Rio de Janeiro, Rio de Janeiro, Brasil.

Pós-Doutora em Serviço Social pela Universidade Federal do Rio de Janeiro.

<mibravo@uol.com.br>

3 Utiliza-se o termo 'contrarreforma', pois ela vai na direção de supressão de direitos, enquanto as reformas têm sua origem nas lutas sociais e progressistas. Para maior aprofundamento, ver Behring (2003). A 'contrarreforma' do Estado, segundo seus idealizadores, pretende modernizar e racionalizar as atividades estatais, redefinidas e distribuídas em quatro setores: o núcleo estratégico, composto pelo legislativo, presidência e cúpula dos ministérios; as atividades exclusivas do Estado, que são as ações de regulamentar, fiscalizar, regular, policiar, fomentar e definir políticas; a 'produção de bens e serviços para o mercado', que é composta por empresas que não cumprem papel estratégico e, portanto, devem ser privatizadas; os 'serviços não exclusivos ou competitivos do Estado', isto é, aqueles que podem ser realizados por instituições não estatais (organizações não governamentais - ONGs), na qualidade de prestadoras de serviço. O Estado pode prover tais serviços, mas não os executa diretamente, nem executa uma política reguladora dessa prestação. Nesses serviços estão incluídas a educação, a saúde, a cultura e as utilidades públicas, entendidas como 'organizações sociais' prestadoras de serviços que celebram 'contratos de gestão' com o Estado (Bresser Pereira, 1996).

4 Segundo Mattos (2012), as OSs qualificadas na área da saúde são: Fundação para o Desenvolvimento Científico e Tecnológico em Saúde (Fiotec); Instituto de Atenção Básica e Avançada à Saúde (Iabas); Associação Paulista para o Desenvolvimento da Medicina, Programa de Atenção Básica e Saúde da Família (SPDM); Associação Global Soluções em Saúde; Pró-Saúde - Associação Beneficente de Assistência Social; Viva Comunidade; Associação Marca para Promoção de Serviços; Instituto SAS; Centro de Apoio ao Movimento Popular - Campo; Instituto Brasileiro de Assistência e Pesquisa (Ibap); Centro de Pesquisa em Saúde Coletiva (Cepesc); Sociedade Espanhola de Beneficência - Hospital Espanhol; Instituto Social Fibra; Instituto Nacional de Benefícios e Assistência às Cooperativas e Associações; Instituto Advance; Casa da Árvore; Centro de Estudos e Pesquisas 28 (CEP 28); Centro Educacional Nosso Mundo (Cenom); Centro de Estudos e Pesquisa Dr. João Amorim (Cejam); Instituto Unir Saúde (IUS); Biotech Humana Organização Social.

${ }^{5}$ Essa lei foi declarada inconstitucional e ilegal pelo Tribunal de Justiça de São Paulo. Em maio de 2012, o Tribunal de Justiça de São Paulo manteve a sua suspensão. O desembargador José Germano, relator do processo, afirmou que "a institucionalização do atendimento aos clientes dos planos particulares, com reserva de $25 \%$ das vagas, nos serviços públicos ou sustentados com os recursos públicos, cria uma anomalia que é a incompatibilização e o conflito entre o público e o privado, com as evidentes dificuldades de controle" (Collucci, 2012). Duas instâncias da Justiça de São Paulo entendem que a lei n. 1.131/2010 e seu decreto regulamentar violam os princípios do SUS. 


\section{Referências}

ADLUNG, Rudolf; CARZANIGA, Antonia. A health services under the General Agreement on Trade in Services. Bulletin WHO, Genebra, v. 79, n. 4, p. 352-364, 2001.

ALMEIDA, Célia. Equidade e reforma setorial na América Latina: um debate necessário. Cadernos de Saúde Pública [on-line], Rio de Janeiro, v. 18, supl., p. S23-S36, 2002. Disponível em: <www.scielo.br/scielo.php?script= sci_arttext\&pid=S0102-311X2002000700004>. Acesso em: 11 out. 2014.

ANDREAZZI, Maria F. S. O seguro saúde privado no Brasil. 1991. 265f. Dissertação (Mestrado em Ciências) - Escola Nacional de Saúde Pública Sergio Arouca. Fundação Oswaldo Cruz, Rio de Janeiro, 1991.

ANDREAZZI, Maria F. S. Recuperação de custos em unidades públicas de saúde: uma contribuição para o debate sobre novas formas de financiamento. RAP: Revista Brasileira de Administração Pública, Rio de Janeiro, v. 31, n. 5, p. 153-190, 1997.

ANDREAZZI, Maria F. S. Privatização de leitos em hospitais públicos no Brasil: debate atual, problemas e impactos. In: ANDREAZZI, Maria F. S.; TURA, Luiz F. R. Financiamento e gestão do setor saúde: novos modelos. Rio de Janeiro: Ed. Anna Néry, 1999. p. 105-132.

ANDREAZZI, Maria F. S. de; KORNIS, George E. M. Padrões de acumulação setorial: finanças e serviços nas transformações contemporâneas da saúde. Ciência \& Saúde Coletiva, Rio de Janeiro, v. 13, n. 5, p. 1.409-1.420, 2008.

\section{ASSEMBLEIA LEGISLATIVA DO ESTADO} DE SÃO PAULO. Parecer da Comissão Parlamentar de Inquérito sobre Remuneração dos Serviços Médico-Hospitalares. São Paulo: Assembleia Legislativa do Estado de são Paulo, 2008. Disponível em: <http://fopspr. files.wordpress.com/2010/08/sub-relatoriocpi-rsmh-oss-hosp-publicos.pdf $>$. Acesso em: 6 maio 2012.
BOITO JR., Armando. A hegemonia neoliberal no governo Lula. Crítica Marxista, Campinas, n. 17, p. 1-25, 2003.

BOSCHETTI, Ivanete. Editorial: o futuro das políticas sociais no governo Lula. Revista Katálysis, Florianópolis, v. 10, n. 1, 2007.

BRAGA, José C. S. Financeirização global. O padrão sistêmico de riqueza do capitalismo contemporâneo. In: TAVARES, Maria C.; FIORI, José L. (Org.) Poder e dinheiro: uma economia política da globalização. Petrópolis: Editora Vozes, 1998. p. 195-242.

BEHRING, Elaine R. Brasil em Contrarreforma. São Paulo: Editora Cortez, 2003.

BRAVO, Maria I. S. B. A política de saúde no governo Lula: algumas reflexões. Revista Inscrita, Brasília, n. 9, p. 35-39, 2004.

BRAVO, Maria I. S. B. Desafios atuais do controle social no Sistema Único de Saúde (SUS). Serviço Social \& Sociedade, São Paulo, n. 88, p.75-100, 2006.

BRAVO, Maria I. S. B.; MENEZES, Juliana S. B. Política de saúde no governo Lula. In: BRAVO, Maria I. S. B. et al. (Org.). Politica de saúde na atual conjuntura: modelos de gestão e agenda para a saúde. Rio de Janeiro: Rede Sirius, 2007. p. 13-21.

BRESSER-PEREIRA, Luiz C. Da administração burocrática à gerencial. Revista do Serviço Público (RSP), Brasília, ano 47, v. 120, n.1, p. 1-28, jan./abr. 1996.

CHESNAIS, François. A mundialização do capital. Rio de Janeiro: Xamã, 1996.

CHESNAIS, François. O capital portador de juros: acumulação, internacionalização, efeitos econômicos e políticos. In: CHESNAIS, François. A finança mundializada: acumulação, internacionalização, efeitos econômicos e políticos. São Paulo: Boitempo Editorial, 2005. p. 35-67. 
COLLUCCI, Cláudia. Tribunal julga atendimento privado em hospitais estaduais de SP. Folha online, 15 maio 2012. Disponível em: <wwwl.folha.uol.com.br/cotidiano/ 1090521-tribunal-julga-atendimento-privadoem-hospitais-estaduais-de-sp.shtml> . Acesso em: 18 maio 2012.

CORDEIRO, Hésio. As empresas médicas. Rio de Janeiro: Graal, 1984.

DOMINGUES, José M. Patrimonialismo e neopatrimonialismo. In: AVRITZER, Leonardo et al. Corrupção: ensaio e críticas. Belo Horizonte: Ed. UFMG, 2008. p. 187-192.

EVANS, Peter. Embedded Autonomy: States in Industrial Transformation. Princeton, NJ: Princeton University Press, 1995.

FAORO, Raimundo. Os donos do poder: formação do patronato político brasileiro. Porto Alegre: Globo, 1958.

FLEURY, Sonia et al. Governança local no sistema descentralizado de saúde no Brasil. Revista Panamericana de Salud Publica, Washington, DC, v. 28, n. 6, p. 446-455, 2010.

GADELHA, Carlos A. G. Saúde e desenvolvimento: uma nova abordagem para uma nova política. Revista de Saúde Pública, São Paulo, v. 46, suspl. 1, dez. 2012. Disponível em: <www.scielosp.org/scielo.php?script= sci_arttext\&pid=S0034-89102012000700002\& lng=en\&nrm=iso > . Acesso em: 16 set. 2013.

GADREY, Jean. L'Économie des services. Paris: Éditions La Découverte, 1996.

GRANEMANN, Sara. Políticas sociais e financeirização dos direitos do trabalho. Em Pauta, Rio de Janeiro, n. 20, p. 57-68, 2007.

HORTA, Maria H.; SOUZA, Carlos F.; WADDINGTON, Sérgio C. Desempenho do setor de serviços no mercado internacional. Rio de Janeiro: Ipea, 1998. (Texto para Discussão; n. 600).

IAMAMOTO, Marilda V. As dimensões ético-políticas e teórico-metodológicas no ser- viço social contemporâneo. In: MOTA, Ana E. M. et al. (Org.). Serviço social e saúde: formação e trabalho profissional. São Paulo: Opas, OMS, Ministério da Saúde, 2006. p. 1-37.

INSTITUTO BRASILEIRO DE GEOGRAFIA E ESTATÍSTICA (IBGE). Estatísticas da saúde: assistência médico-sanitária 2009. Rio de Janeiro: IBGE, 2009.

LABRA, Maria E. Política e saúde no Chile e no Brasil: contribuições para uma comparação. Ciência \& Saúde Coletiva [on line], Rio de Janeiro, v. 6, n. 2, p. 361-376, 2001.

LAURELL, Asa C. Estado y politicas sociales em el neoliberalismo. Mexico, DF: Fundación F. Ebert, 1992.

LAZZARINI, Sérgio G. Capitalismo de laços. São Paulo: Campus/Elsevier, 2010.

MACHADO, Cristiani V. Contexto, atores, instituições: um estudo exploratório acerca das novas modalidades de gerência nos hospitais públicos do município do Rio de Janeiro nos anos 90. 1990. Dissertação (Mestrado em Saúde Coletiva) - Instituto de Medicina Social, Universidade do Estado do Rio de Janeiro, Rio de Janeiro, 1999.

MARQUES, Rosa M.; MENDES, Áquilas. Desvendando o social no governo Lula: a construção de uma nova base de apoio. In: PAULA, João A. (Org.). Adeus ao desenvolvimento: a opção do governo Lula. Belo Horizonte: Autêntica, 2005. p. 143-170.

MARTINS, Humberto F. Em busca de uma teoria da burocracia pública não-estatal: política e administração no terceiro setor. Revista de Administração Contemporânea, Rio de Janeiro, v. 2, n. 3, p. 109-128, set./dez. 1998.

MARX, Karl. O capital: crítica da economia política. Rio de Janeiro: Civilização Brasileira, 1980

MARX, Karl. O capital: livro segundo - o processo de circulação do capital. Editado por Friedrich Engels. São Paulo: Abril Cultural, 1984 [1885]. (Coleção Os Economistas, v. 3). 
MATTOS, Ruben A. de. As agências internacionais e as políticas de saúde nos anos 90: um panorama geral da oferta de idéias. Ciência \& Saúde Coletiva, Rio de Janeiro, v. 6, n. 2 , p. $377-389,2001$.

MATTOS, Vivian de A. Serviço social: cotidiano profissional nas unidades de pronto atendimento geridas por organizações sociais no município do Rio de Janeiro. Dissertação (Mestrado em Serviço Social) - Universidade do Estado do Rio de Janeiro, Rio de Janeiro, 2012.

MENDES, Eugênio V. Os grandes dilemas do SUS. Salvador: Casa da Qualidade, 2001.

NOGUEIRA, Roberto P. O desenvolvimento federativo do SUS e as novas modalidades institucionais de gerência das unidades assistenciais. In: SANTOS, Nelson R. dos; AMARANTE, Paulo D. de. C. (Orgs.). Gestão pública e relação público-privado na saúde. Rio de Janeiro: Cebes, 2010. p. 24-47.

O ESTADO DE S. PAULO. São Paulo fará parceria de R\$ 6 bilhões na área da saúde. O Estado de S. Paulo, São Paulo, 18 nov. 2010. Disponível em: <www.estadao.com. br/noticias/geral,sao-paulo-fara-parceria-der-6-bilhoes-na-area-da-saude,641664,0.htm>. Acesso em: 6 maio 2012.

PAIM, Jairnilson S.; TEIXEIRA, Carmem F. Configuração institucional e gestão do Sistema Único de Saúde: problemas e desafios. Ciência \& Saúde Coletiva [on line], Rio de Janeiro, v. 12, supl., p. 1.819-1.829, 2007. Disponível em: <www.scielo.br/scielo.php?script= sci_arttext\&pid=S0103-73312008000400003 > . Acesso em: 9 jul. 2014.

PINTO, Elida G. Organizações sociais e reforma do estado no Brasil: riscos e desafios nesta forma de institucionalizar a parceria estado-sociedade organizada. CONCURSO DE ENSAYOS DEL CLAD “ADMINISTRACIÓN PÚBLICA Y CIUDADANÍA", 14. Caracas, 2000 .

REDAÇÃO MAIS COMUNIDADE. Intervenção no Hospital de Santa Maria começa hoje.
Brasília, 11 nov. 2010. Disponível em: <www. secom.unb.br/unbcliping2/cpmod.php?id= 78360 > . Acesso em: 6 maio 2012.

RIO DE JANEIRO. Agência Nacional de Saúde Suplementar (ANS). Dados sobre beneficiários de planos privados de assistência a saúde. Rio de Janeiro. ANS, 2013.

RIZZOTTO, Maria L. F. O Banco Mundial e as politicas de saúde no Brasil nos anos 90: um projeto de desmonte do SUS. Tese (Doutorado em Saúde Coletiva) - Faculdade de Ciências Médicas da Universidade Estadual de Campinas, 2000.

SALMON, Jack W. Profit and health care: trends in corporatization and proprietization. International Journal of Health Services, Baltimore, v. 15, n. 3, p. 395-418, 1985.

SANO, Hironobu; ABRUCIO, Fernando L. Promessas e resultados da nova gestão pública no Brasil: o caso das organizações sociais de saúde em São Paulo. Revista de Administração de Empresas, São Paulo, v. 48, n. 3, p. 64-80, 2008.

SANTOS, Maria Angélica B. dos.; PASSOS, Sonia R. L. Comércio internacional de serviços e complexo industrial da saúde: implicações para os sistemas nacionais de saúde. Cadernos de Saúde Pública, Rio de Janeiro, v. 26, n. 8, p. 1.483-1.493, 2010.

SÃO PAULO. Assembleia Legislativa do Estado de São Paulo (Alesp). Parecer do Deputado Estadual Raul Marcelo, PSol/SP. São Paulo: ALESP, 10 de abril de 2008. Disponível em: <http://fopspr.files.wordpress.com/ 2010/08/sub-relatorio-cpi-rsmh-oss-hosppublicos.pdf>. Acesso em: 6 maio 2012.

SODRÉ, Nelson W. Formação histórica do Brasil. São Paulo: Brasiliense, 1962.

WORLD BANK. Report n. 36601-BR. Governance in Brazil's Unified Health System (SUS). Raising the quality of public spending and resource management, 2007. Disponível em: <www-wds.worldbank.org/external/ default/WDSContentServer/WDSP/IB/2007/ 
03/06/000090341_20070306085417/Rendered/ PDF/366010BR.pdf>. Acesso em: 18 jul. 2011.

Recebido em 15/01/2013

Aprovado em 21/08/2013 